\title{
Optical Properties of Direct Restorative Materials
}

\author{
Y. MIYAGAWA, * J. M. POWERS, ${ }^{\dagger}$ and W. J. O'BRIEN ${ }^{\dagger}$
}

${ }^{*}$ Department of Dental Materials Science, Nippon Dental University, Niigata, Japan and ${ }^{\dagger}$ The University
of Michigan, School of Dentistry, Ann Arbor, Michigan 48109

The contrast ratio, light reflectivity, scattering coefficient, and absorption coefficient of four composites and an unfilled resin were calculated algebraically from reflection spectrophotometric data using Kubelka's equations. The correlation coefficient between calculated and experimental values of contrast ratio was 0.9996 . Values of infinite optical thickness ranged from 4.19 to $6.70 \mathrm{~mm}$.

J Dent Res 60(5):890-894, May 1981

\section{Introduction.}

Opacity is an important property of esthetic dental restorations. The contrast ratio, which describes opacity, depends upon the thickness of the material and the reflectance of the backing. ${ }^{1}$ The relationship between reflectance and thickness of a translucent material has been studied theoretically by Kubelka and Munk. ${ }^{2}$ Several authors ${ }^{3-5}$ have applied the Kubelka-Munk theory to obtain optical constants of esthetic dental filling materials (mostly dental silicate cements); however, the Kubelka-Munk formulas do not lend themselves to algebraic solution. Therefore, graphic aids ${ }^{3,5}$ developed by Judd $^{6}$ or a least-squares curvefitting computer program ${ }^{4}$ were required to obtain the optical constants. In 1948,

Received for publication May 23, 1980

Accepted for publication July 1,1980

This investigation was presented in part at the 58 th General Session of the International Association for Dental Research in Osaka, Japan, June, 1980.

The cooperation of the following companies in providing commercial products is acknowledged: L.D. Caulk Co., Lee Pharmaceuticals, and 3M Co.

Dr. Miyagawa acknowledges the financial support of his position as Visiting Scholar at The University of Michigan from July, 1979, to March, 1981, from Nippon Dental University, Niigata, Japan.

Dr. O'Brien acknowledges the financial support of Research Grant DE-05423 from the National Institute of Dental Research, National Institutes of Health, Bethesda, MD 20205.
Kubelka ${ }^{7}$ developed a theory and derived equations for optical properties that could be solved algebraically by hyperbolic functions.

The purpose of this study was to calculate optical constants from the reflection spectrophotometric data of four composites and an unfilled resin reported previously 1 and to calculate the opacity of samples of different thicknesses algebraically. Further, the agreement between calculated and observed values of opacity was examined to evaluate the validity of Kubelka's equations applied to materials more complex than the simplified model for which the theory was developed.

\section{Materials and methods.}

Four commercial composites and an unfilled restorative resin were studied. Codes, shades, batch numbers, and manufacturers of the materials are listed in Table 1 .

Three sample disks $(36 \mathrm{~mm}$ in diameter and $1.3 \mathrm{~mm}$ in thickness) were made for each product by polymerizing the resin in a metal die. The samples were placed in an oven at $37^{\circ} \mathrm{C}$ within $90 \mathrm{~s}$ after initiating the mix and were stored for $24 \mathrm{~h}$ before testing. Specimens of the material (NF) activated by ultraviolet light were polymerized in the die by exposing the open side through a thin glass plate to an ultraviolet light source* for two min at a distance of $5 \mathrm{~cm}$.

Three samples at each of two additional thicknesses were obtained by placing any two of the $1.3 \mathrm{~mm}$ samples $(\mathrm{p}, \mathrm{q}$, or $\mathrm{r}$ ) together to form $2.6 \mathrm{~mm}$ samples (i.e., $\mathrm{pq}, \mathrm{qr}$, and $\mathrm{rp}$ ) and by placing all three of the $1.3 \mathrm{~mm}$ samples together to form 3.9 $\mathrm{mm}$ samples (i.e., pqr, qrp, and rpq).

Curves of percent reflectance versus wavelength $(\lambda)$ were obtained for three replications of each thickness (1.3, 2.6,

*Blak-Ray, model B-100 A, Ultra-Violet Products, Inc., San Gabriel, CA 91775 
TABLE 1

CODES, PRODUCTS, BATCH NUMBERS, AND MANUFACTURERS OF RESTORATIVE MATERIALS

\begin{tabular}{|c|c|c|c|c|}
\hline \multirow{2}{*}{$\frac{\text { Code }}{\text { C }}$} & \multirow{2}{*}{\begin{tabular}{l}
\multicolumn{1}{c}{ Product } \\
Concise \\
(Universal)
\end{tabular}} & \multicolumn{2}{|c|}{ Batch Number } & \multirow{2}{*}{$\begin{array}{l}\text { Manufacturer } \\
\text { 3M Co. } \\
\text { St. Paul, MN } 55101\end{array}$} \\
\hline & & $\begin{array}{l}\text { base } \\
\text { catalyst }\end{array}$ & $\begin{array}{l}7080 \mathrm{E} 12 \\
7080 \mathrm{E} 12\end{array}$ & \\
\hline NF & $\begin{array}{l}\text { Nuva-Fil } \\
\text { (Light) }\end{array}$ & $\begin{array}{l}\text { base } \\
\text { catalyst }\end{array}$ & $\begin{array}{l}052877 \\
120276\end{array}$ & $\begin{array}{l}\text { L.D. Caulk Co. } \\
\text { Div. of Dentsply Interna- } \\
\text { tional, Inc. } \\
\text { Milford, DE } 19963\end{array}$ \\
\hline $\mathbf{P}$ & $\begin{array}{l}\text { Prestige } \\
\text { (Universal) }\end{array}$ & $\begin{array}{l}\text { base } \\
\text { catalyst }\end{array}$ & $\begin{array}{l}\text { MS0015 } \\
\text { MS0021 }\end{array}$ & $\begin{array}{l}\text { Lee Pharmaceuticals } \\
\text { South E1 Monte, CA } 91733\end{array}$ \\
\hline SV & $\begin{array}{l}\text { Sevriton } \\
\text { (S5-Light Yellow) }\end{array}$ & $\begin{array}{l}\text { liquid } \\
\text { powder }\end{array}$ & $\begin{array}{l}\text { SG29SK } \\
\text { PH26PH }\end{array}$ & $\begin{array}{l}\text { Amalgamated Dental Trade } \\
\text { Dist., L td. } \\
\text { London, England }\end{array}$ \\
\hline V & $\begin{array}{l}\text { Vytol } \\
\text { (Light) }\end{array}$ & $\begin{array}{l}\text { base } \\
\text { catalyst }\end{array}$ & $\begin{array}{l}042077 \\
050477\end{array}$ & L.D. Caulk Co. \\
\hline
\end{tabular}

and $3.9 \mathrm{~mm}$ ) for each material between 405 and $700 \mathrm{~nm}$ with a double-beam ultraviolet-visible spectrophotometert and integrating sphere. $\$$ Each specimen was evaluated in the sample port $(25 \mathrm{~mm}$ in diameter) under two conditions for combined specular and diffuse reflectance: 1) backed by a black standard $\$$ and 2 ) backed by a white standard. ${ }^{\infty}$ A second white standard was used in the reference port for calibration of zero and $100 \%$ reflectance and to obtain data. The arithmetic average roughness of the examined surface of a sample was $2.5 \mu \mathrm{m}$ as measured from profile tracings. " Tristimulus values $(X, Y, Z)$ relative to the $1931 \mathrm{CIE}^{* *}$ color-matching functions for CIE standard illuminant $\mathrm{C}$ were determined by numerical integration $(\Delta \lambda=5 \mathrm{~nm})$ as described elsewhere. ${ }^{8}$ Only values of $\mathrm{Y}$ were used in the following calculations.

The optical constants including light reflectivity $\left(R_{\infty}\right)$, scattering coefficient $(S)$, and absorption coefficient $(\mathrm{K})$ were calculated algebraically from the reflection spectrophotometric data of the $1.3 \mathrm{~mm}$

†ACTA C III UV-Visible Spectrophotometer, Beckman Instruments, Inc., Irvine, CA 92664

\$ASPH-U Integrating Sphere, Beckman Instruments, Inc., Irvine, CA 92664

$\S$ Part No. 375286, Beckman Instruments, Inc., Irvine, CA 92664

${ }^{\infty}$ Part No. 375285, Beckman Instruments, Inc., Irvine, CA 92664

I Surfanalyzer 150, Gould, Inc., Instrument Systems Division, Cleveland, OH 44114

**International Commission on Illumination samples of each material using Kubelka's equations ${ }^{7}$ as described below.

Secondary optical constants (a and b) were calculated from the experimentallyobtained tristimulus values for black $\left(Y_{O}\right)$ and white $(\mathrm{Y})$ backings by equations 1 and 2:

$$
\begin{gathered}
a=1 / 2\left[R+\left(R_{o}-R+R_{g}\right) / R_{o} R_{g}\right] \\
\text { and } \\
b=\left(a^{2}-1\right)^{1 / 2},
\end{gathered}
$$

where $R_{g}$ is the reflectance of a white backing $(0.899$ for the white standard used), $\mathrm{R}_{\mathrm{o}}$ is the light reflectance of a sample with a black backing $\left(0.899 \mathrm{Y}_{\mathrm{o}} / 100\right)$, and $\mathrm{R}$ is the light reflectance of a sample with the white backing $(0.899 \mathrm{Y} / 100)$.

The light reflectivity ( $R_{\infty}$, the light reflectance of a material of infinite thickness) is defined by equation 3 :

$$
\mathrm{R}_{\infty}=\mathrm{a}-\mathrm{b} .
$$

The scattering coefficient (S) for a unit thickness of a material is defined by equation 4:

$$
S=\frac{1}{b X} \operatorname{Arctgh} \frac{\left(1-a R_{o}\right)}{b R_{o}}, m^{-1},
$$

where $X$ is the thickness of the sample, ctgh is a hyperbolic co-tangent and $\mathrm{Ar}$ ctgh is an inverse hyperbolic co-tangent (area function). 
The absorption coefficient $(\mathrm{K})$ is defined by equation 5 :

$$
\mathrm{K}=\mathrm{S}(\mathrm{a}-1), \mathrm{mm}^{-1} .
$$

Once $a, b$, and $S$ are obtained, the light reflectance $(R)$ for a sample of any thickness $(X)$ in contact with a backing of any reflectance $\left(R_{g}\right)$ can be calculated from equation 6 :

$$
\mathrm{R}=\frac{1-\mathrm{R}_{\mathrm{g}}(\mathrm{a}-\mathrm{b} \operatorname{ctgh} \mathrm{bSX})}{\mathrm{a}+\mathrm{b} \operatorname{ctgh} \mathrm{bSX}-\mathrm{R}_{\mathrm{g}}} ;
$$

then, an estimate of the opacity can be obtained by the contrast ratio (CR), $R_{o} / R$.

In this study, the obtained optical constants for the $1.3 \mathrm{~mm}$ samples were used to calculate the contrast ratio (CR) of $2.6 \mathrm{~mm}$ and $3.9 \mathrm{~mm}$ samples for the white backing used $\left(R_{g}=0.899\right)$. The calculated $C R$ was compared to the mean of the observed CR, which was obtained directly from the reflection spectrophotometric data of $2.6 \mathrm{~mm}$ and $3.9 \mathrm{~mm}$ samples for each material. Also, the thickness of a material $\left(\mathrm{X}^{\prime}{ }_{\infty}\right)$ which is regarded to be of infinite thickness optically was calculated from equation 4 by substituting $0.999 \mathrm{R}_{\infty}$ for $\mathrm{R}_{0}$.

\section{Results.}

Mean values and standard deviations of $R, R_{o}$, and CR which were obtained directly from the spectrophotometric data of 1.3 $\mathrm{mm}$ samples are listed in Table 2. Mean values and standard deviations of $R_{\infty}, S, K$, and $\mathrm{X}_{\infty}^{\prime}$ which were calculated using Kubelka's equations are listed in Table 3. These data were studied using a one-way analysis of variance. 9 There were significant differences among materials for mean values of $R_{\infty}, S, K$, and $X_{\infty}^{\prime}$ at the $95 \%$ level of confidence. Tukey's intervals ${ }^{10}$ calculated for comparisons among means at the 0.05 level of significance are also listed in Table 3 . The light reflectivity $\left(\mathrm{R}_{\infty}\right)$ of NF, V, and SV was much higher than that of $C$ and $P$. SV and $P$ attained values of light reflectivity $\left(R_{\infty}\right)$ at much thinner layers of materials than $\mathrm{V}$ and $\mathrm{C}$; NF required the thickest layer to attain $R_{\infty}$.

The observed and calculated values of CR of $2.6 \mathrm{~mm}$ and $3.9 \mathrm{~mm}$ samples of each material are shown in the Figure with a dashed line indicating a $1: 1$ relationship. The correlation coefficient ( $r$ ) between the observed $\left(C R_{o}\right)$ and calculated $\left(C R_{c}\right)$ values was computed ${ }^{9}$ to be 0.9996 . The critical value of $r$ above which the hypothesis of independence of $C R_{O}$ and $C R_{c}$ could be rejected was 0.632 at the $95 \%$ level of confidence. The slope of the regression line ${ }^{9}$ of $\mathrm{CR}_{\mathrm{c}}$ versus $\mathrm{CR}_{\mathrm{o}}$ was 0.9995 with a standard error of 0.0006 .

\section{Discussion.}

The Kubelka-Munk theory ${ }^{7}$ describes the optical properties of a plane turbid material of constant finite thickness. Edge effects are neglected and optical inhomogeneities are assumed to be much smaller than specimen thickness and are uniformly distributed. The theory ignores reflections from boundaries of media of different refractive indices and the change of wavelength distribution by specific absorption or by dispersion of light. In spite of these restrictions, the agreement obtained between calculated and experimental values of contrast ratio was very good for the restorative materials studied.

The application of Kubelka's equations to the Kubelka-Munk theory allows the algebraic determination of optical constants of esthetic dental restorative materials from reflectance values of a sample of known

TABLE 2

SPECTROPHOTOMETRIC PARAMETERS OF 1.3-mm-THICK SAMPLES

\begin{tabular}{llll}
\hline \hline Material & \multicolumn{1}{c}{$\mathrm{R}^{\dagger}$} & $\mathrm{R}_{\mathrm{o}}$ & $\mathrm{CR} \dagger$ \\
\hline $\mathrm{C}$ & $0.541(0.005)^{*}$ & $0.332(0.005)$ & $0.614(0.004)$ \\
$\mathrm{NF}$ & $0.663(0.003)$ & $0.421(0.005)$ & $0.635(0.007)$ \\
$\mathrm{P}$ & $0.480(0.021)$ & $0.343(0.010)$ & $0.715(0.020)$ \\
SV & $0.563(0.003)$ & $0.446(0.014)$ & $0.793(0.028)$ \\
V & $0.624(0.006)$ & $0.425(0.009)$ & $0.681(0.016)$ \\
\hline
\end{tabular}

*Mean value of three replications with standard deviation in parentheses.

†The reflectance of the white backing used was 0.899 . 
TABLE 3

OPTICAL CONSTANTS OF MATERIALS TESTED

\begin{tabular}{lllcl}
\hline \hline Material & \multicolumn{1}{c}{$\mathrm{R}_{\infty}$} & $\mathrm{S}\left(\mathrm{mm}^{-1}\right)$ & $\mathrm{K}\left(\mathrm{mm}^{-1}\right)$ & $\mathrm{X}_{\infty}^{\prime}(\mathrm{mm})$ \\
\hline $\mathrm{C}$ & $0.409(0.007)^{*}$ & $0.576(0.012)$ & $0.246(0.004)$ & $5.74(0.01)$ \\
$\mathrm{NF}$ & $0.537(0.004)$ & $0.740(0.017)$ & $0.148(0.003)$ & $6.70(0.11)$ \\
P & $0.390(0.014)$ & $0.696(0.026)$ & $0.332(0.029)$ & $4.45(0.27)$ \\
SV & $0.496(0.007)$ & $1.044(0.095)$ & $0.267(0.013)$ & $4.19(0.28)$ \\
V & $0.515(0.006)$ & $0.808(0.036)$ & $0.184(0.007)$ & $5.74(0.21)$ \\
\hline Tukey's & & & & \\
Interval & 0.023 & 0.129 & 0.039 & 0.54 \\
\hline
\end{tabular}

*Mean value of three replications with standard deviation in parentheses.

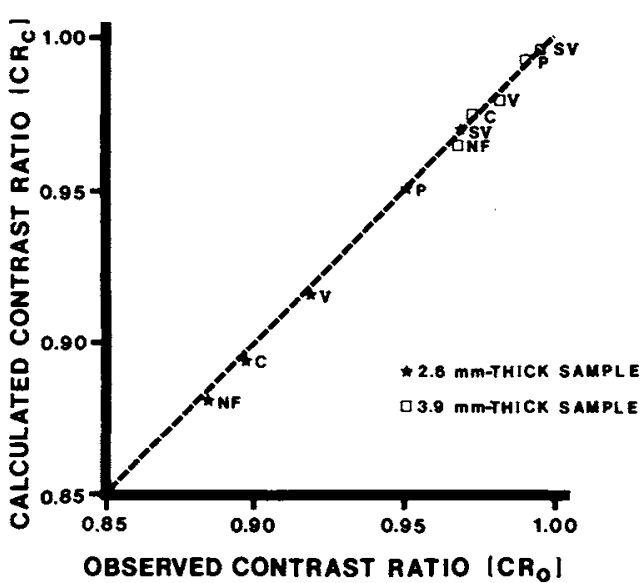

Fig. - Calculated versus observed values of contrast ratio of 2.6 - and $3.9-\mathrm{mm}$-thick samples of four composites and an unfilled restorative resin. The reflectance $\left(\mathrm{R}_{\mathrm{g}}\right)$ of the white backing was 0.899 .

thickness against two backings of different reflectance. It should be noted, however, that the predictions calculated from these optical constants might become inaccurate under different experimental conditions. For example, the presence of a film of matter on the surface of the material or a change in the angle of incidence of the illuminating source could affect the results by changes in the Fresnel reflectance. 11

The clinical implication of this in vitro study is that the color of an esthetic restorative material of a thickness less than $X^{\prime}$. is dependent on the color of the background and the thickness of the restoration. Among the materials tested, $\mathrm{X}^{\prime}$. ranged from 4.19 to $6.70 \mathrm{~mm}$; thus, typical anterior restorations made from these materials would appear translucent, and a color match would be dependent on the background, as well as the shade of the restorative material. Present- ly, esthetic restorative materials are described only by a shade. Perhaps the optical properties (such as $\mathrm{X}_{\infty}^{\prime}$ ) of the material should be described in addition. Further study should examine the relationship of excitation purity and dominant wavelength to optical constants.

\section{Conclusions.}

The optical constants including light reflectivity, scattering coefficient, and absorption coefficient of four composites and an unfilled restorative resin were calculated algebraically using Kubelka's equations from reflection spectrophotometric data of 1.3mm-thick samples against black and white backings. The contrast ratios of $2.6-\mathrm{mm}-$ thick and 3.9-mm-thick samples were calculated using optical constants based upon the Kubelka-Munk theory. The calculated values were compared to values obtained experimentally. There were no significant differences between the observed and calculated values with a correlation coefficient of 0.9996. Values of infinite optical thickness ranged from 4.19 to $6.70 \mathrm{~mm}$ for the materials tested. Color of esthetic restorative materials in vitro depends on shade, thickness, and background color.

\section{REFERENCES}

1. POWERS, J.M.; DENNISON, J.B.; and LEPEAK, P.J.: Parameters that Affect the Color of Direct Restorative Resins, $J$ Dent Res 57:876-880, 1978.

2. KUBELKA, P. and MUNK, F.: Ein Beitrag zur Optik det Farbanstriche, Zeit Tech Phys 12:593-601, 1931.

3. PAFFENBARGER, G.C.: Dental Silicate Cements, in: Judd, D.B., Optical Specification of Light-scattering Materials: RP 1026, $J$ Res Nat Bur Standards 19:314-316, 1937. 
4. STOREY, B.E. and JEFFREY, I.W.M.: The Clinical Implications of Some Optical Properties of Silicate Cement, $J$ Dent 2:77-84, 1973/74.

5. CRISP, S.; ABEL, G.; and WILSON, A.D.: The Quantitative Measurement of the Opacity of Aesthetic Dental Filling Materials, J Dent Res 58:1585-1596, 1979.

6. JUDD, D.B.: Optical Specification of Lightscattering Materials, RP 1026, J Res Nat Bur Standards 19:287-317, 1937.

7. KUBELKA, P.: New Contributions to the Optics of Intensely Light-scattering Materials. Part I, J Opt Soc Am 38:448-457, 1948.
8. WYSZECKI, G. and STILES, W.S.: Color Science, New York: Wiley and Sons, Inc., 1967, p. 276.

9. University of Michigan, Statistical Research Laboratory: A Manual of Elementary Statistics using MIDAS, Ann Arbor, Statistical Research Laboratory, 1975, 301 p.

10. GUENTHER, W.C.: Analysis of Variance, Englewood Cliffs, NJ: Prentice-Hall, 1964, $199 \mathrm{p}$.

11. JUDD, D.B.: Fresnel Reflection of Diffusely Incident Light, RP 1504, J Res Nat Bur Standards 29:329-332, 1942.

"The author requests that the illustration below be substituted for the one appearing on page 2196, J Dent Res 59 (D2), December, 1980."

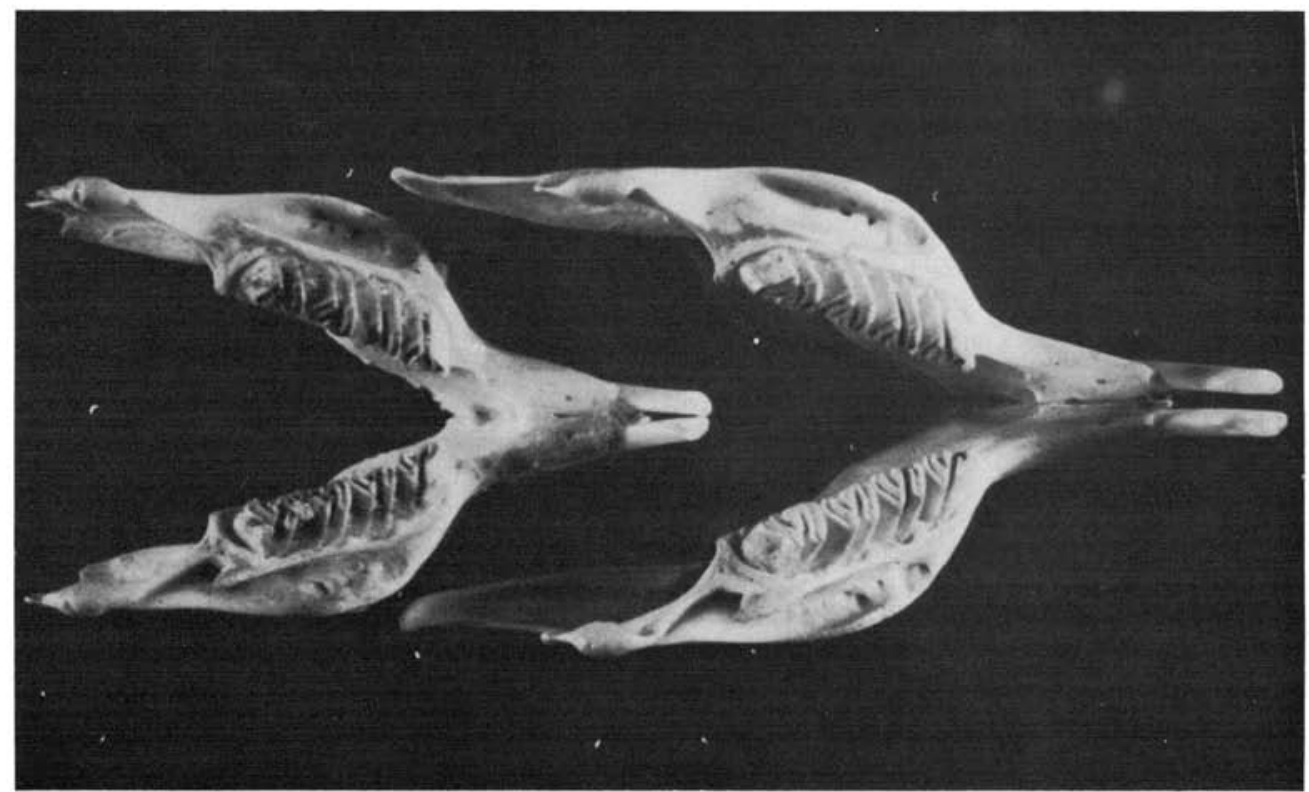

Fig. 2 - These guinea pig mandibles are representative of ascorbate deficient animals (left) and ad libitum control animals (right). Although the ad libitum mandible is obviously larger than the deficient mandible, note that the dental arch length is comparable in both mandibles. This illustrates the differential effect of nutrition on tooth $v s$. jaw growth. 